\title{
MRS Takes the Lead in Materials Research Public Outreach
}

At the centennial meeting of the American Physical Society in March, Department of Energy Secretary Bill Richardson implored the physics community to make their science more comprehensible to the public. In a particularly strongly worded part of his speech, reproduced from the FYI newsletter of the American Institute of Physics, Secretary Richardson said, "What we need to dowhat you need to do-is to better translate physics into plain English. Into examples we can all understand, and why it matters to them and to the country. In contrast, the public has an easier perception of the importance of funding the life sciences."

With the insertion of "materials" or "materials research" into Richardson's statement for "physics," the same message could have been delivered to the Materials Research Society during the recent celebration of our 25 th anniversary. Like physics, the materials community has a public identity problem, and the problem is probably a more serious one than that of physics. Much of the public at least knows about physics as a science, and a decent number of people had to take it in high school. I often fear that "materials" to the broad public means the stuff clothes and curtains are made of and is purchased at a fabric shop. Because of its objective to foster interdisciplinary materials research, MRS must take the lead in the materials community in reaching out to the public to show that what we do matters to their well-being.

Fortunately, MRS is actively taking the Secretary's message to heart in many new ways in recent years. The Academic Affairs Committee has steadily increased its interest range to undergraduate activities. The

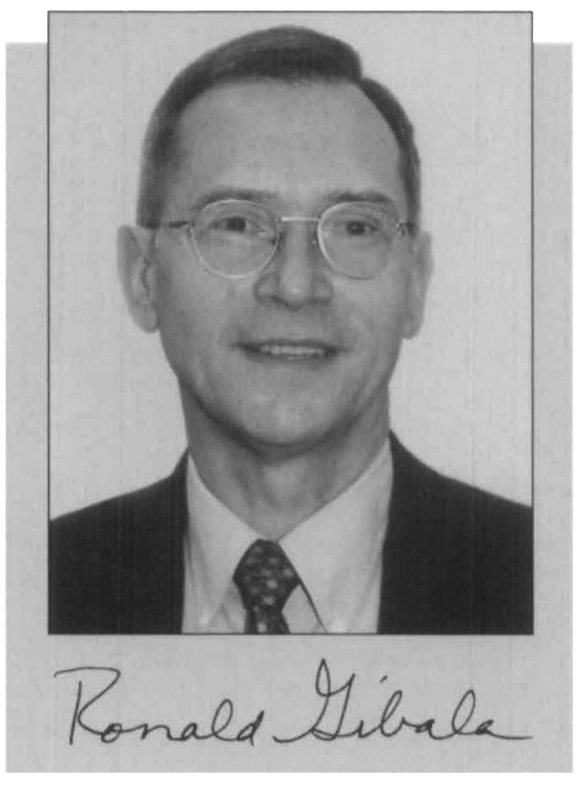

recent unqualified success of the Undergraduate Materials Research Initiative and the increased participation of MRS in undergraduate accreditation of materials programs through ABET illustrate some of the evolutionary changes. During this year, the Public Affairs Committee had bifurcated itself into two major subcommittees: Government Affairs, which it has done in excellent fashion for several years, and Public Outreach, which we hope will bring additional focus on the types of efforts Secretary Richardson calls for. The proactive effort of the Committee to identify public outreach as a major segment of its activities is an exciting step for MRS. We now need a solid strategic plan with several action projects.

Perhaps the most exciting and revolu- tionary of recent MRS outreach projects is the proposal to develop a nationally traveling exhibit that interprets basic principles of physics and chemistry in materials science and identifies the elements of structure-properties-processing-performance interrelationships as they apply in our work as materials researchers. The exhibit, entitled "Materials MicroWorld," is proposed to have a modular design that enables a $4500 \mathrm{ft}^{2}$ installation in large museums and a $2500 \mathrm{ft}^{2}$ version for smaller museums or other sites. The exhibit plans to contain discovery stations, handson models, and many other demonstration forms of the science and technology of materials that are intended to engage a wide range of public audiences, from preschool children to adults.

Although initial concept drawings for the exhibit have been submitted to the National Science Foundation for partial funding of the project, there is ample space for the creative ideas of MRS members and affiliated organizations. Just as the concept drawings were developed with the input of attendees at the 1998 MRS Fall Meeting, the exhibit will require the participation of MRS members as demonstrators when it comes to a museum or center near their residential areas. Please volunteer now or be enthusiastically available when asked later. The long-term goal is that Secretary Richardson's message will one day not apply to the public's knowledge of materials research and its profoundly positive societal consequences.

RON GIBALA 1999 MRS PRESIDENT rgibala@sandia.gov rgibala@umich.edu

\section{ACCESS THE MATERIALS RESEARCH SOCIETY PUBLIC AFFAIRS WEBSITE for links to Policies in Science and Technology www.mrs.org/pa/policy/}

\section{LINKS INCLUDE:}

- FYl-by Audrey Leath and Richard Jones, American Institute of Physics: FYI summarizes science policy developments in Washington affecting the science and technology community. Summaries are approximately one page long and are issued two or more times every week. FYl subscriptions are free; they are provided by AIP as a service to the science community.

- Centre for Policy Research on Science and Technology: The Centre for Policy Research on Science and Technology at Simon Fraser University in Canada was established in 1980 to conduct focused research on the relationship between public policy, the management of technology, and innovation.
- Parliamentary Office of Science and Technology (U.K.): POST is an office of the United Kingdom's Houses of Parliament, which is charged with providing balanced and objective analysis of the science- and technology-based issues.

- The Rand Corporation: A U.S. premier think-tank, Rand Corporation conducts public policy research and analysis, including science- and technology-related issues, for the government, industry, and other sponsors.

- Technology and Innovation Policy Information Map: An aftempt to create a comprehensive listing of science, technology, and innovation policy resources on the Internet. 


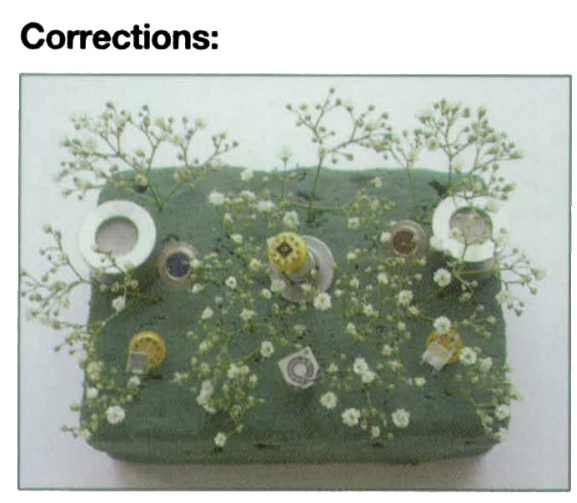

The gas sensors on the cover of the June 1999 issue of MRS Bulletin were arranged by Margaret Watson and photographed by Malcolm Bowen (see above).

An error was made in the June 1999 issue of MRS Bulletin, page 34, in the article, "Thick-Film Gas Sensors Based on NanoSized Semiconducting Oxide Powders," by G. Martinelli, M.C. Carotta, E. Traversa, and G. Ghiotti. Figure 6 was reproduced as Figure 7. See Figure 7 to the right for the correct version.

Sony provided Symposium Support for Symposium R at the 1999 MRS Spring Meeting; for the other supporters, see the July 1999 issue of MRS Bulletin, page 59.

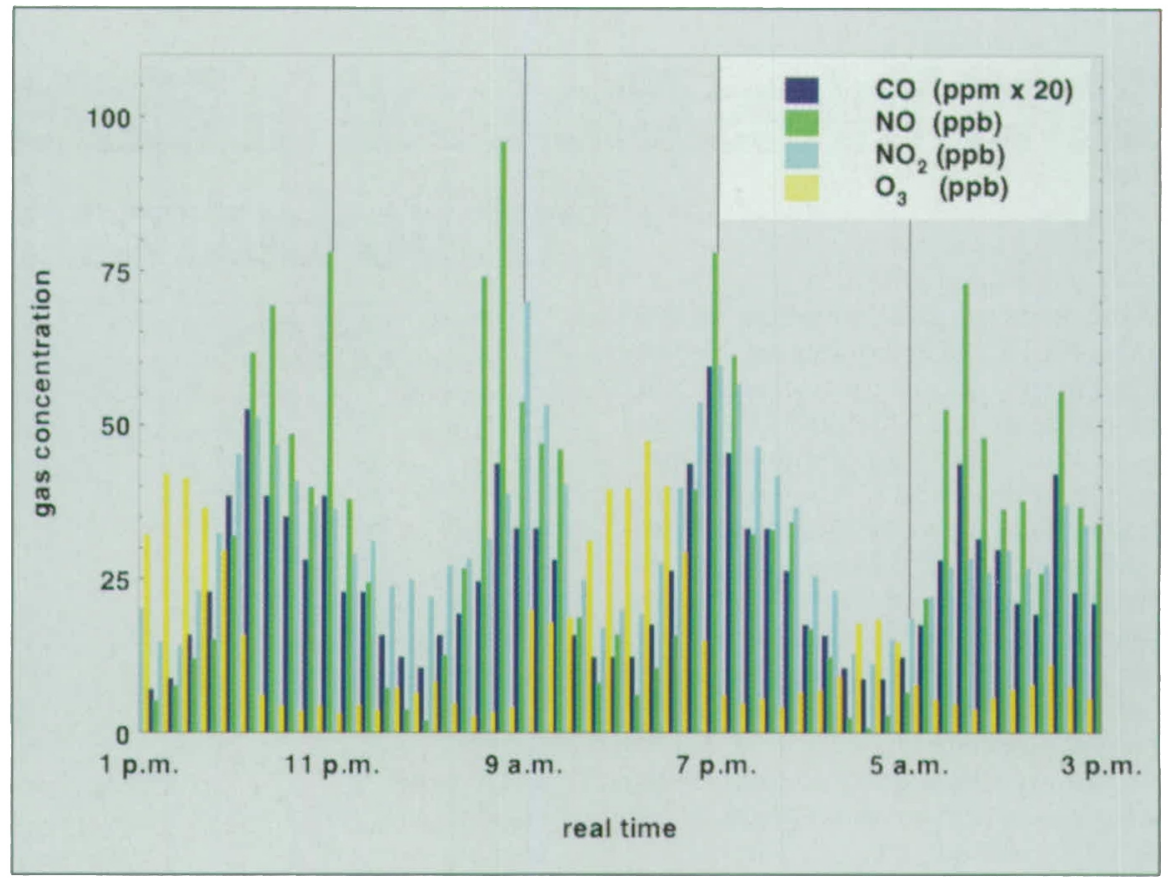

Figure 7. Values of $\mathrm{CO}, \mathrm{NO}, \mathrm{NO}_{2}$, and $\mathrm{O}_{3}$ concentrations measured with analytical equipment managed by ARPA, during field tests between September 23 and 25, 1998.

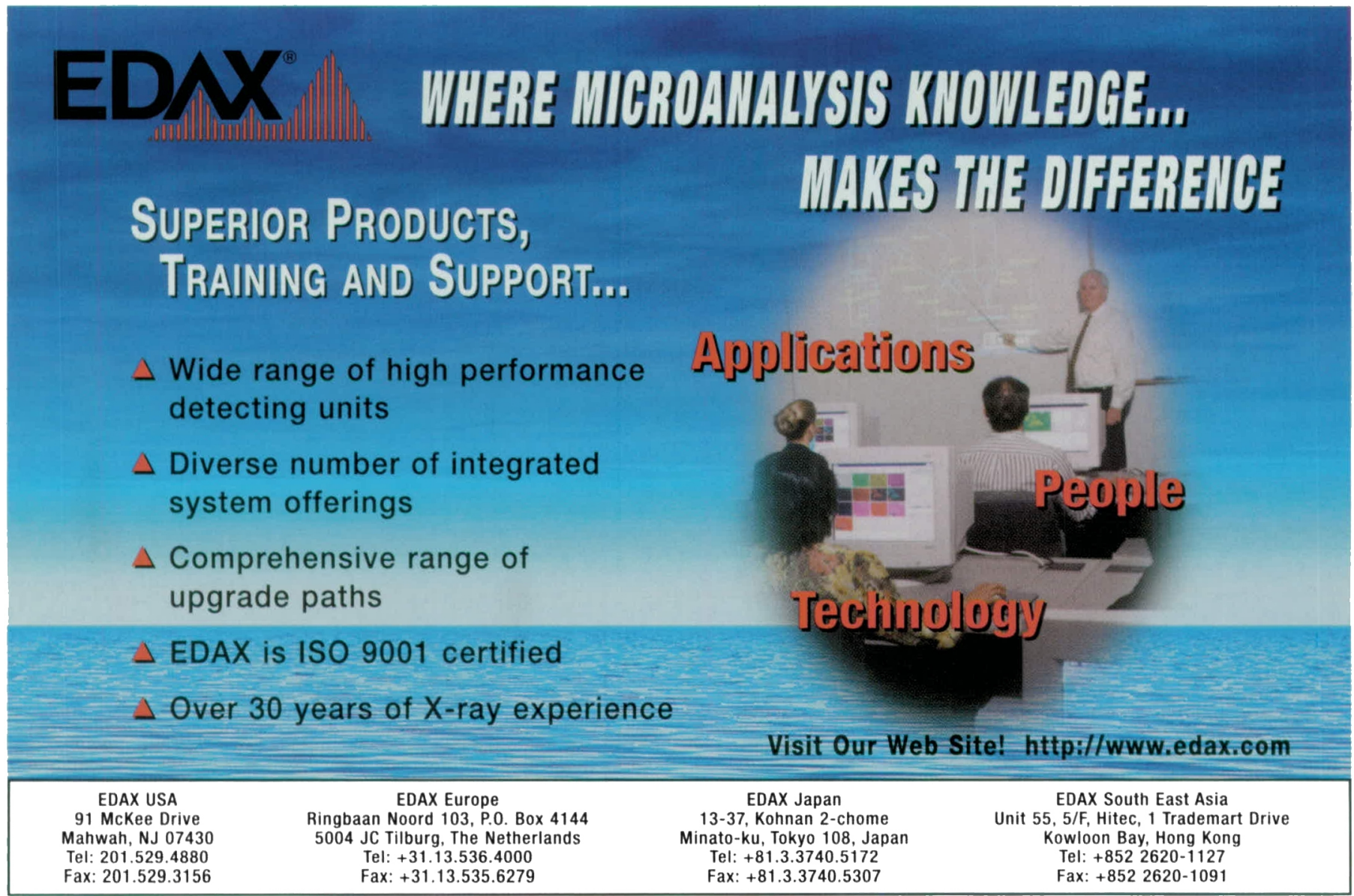

Circle No. 5 on Reader Service Card. 